\title{
Titanium Dioxide Nanotubes for Speciation of Inorganic Arsenic in Environmental Water Samples by ICP-MS
}

\author{
Shizhong Chen*, Xinle Guo, Yuanyuan He, and Dengbo Lu \\ College of Chemical and Environmental Engineering, Wuhan Polytechnic University \\ 68 Xuefu South Road Changqing Garden, Wuhan 430023, P.R. China
}

\section{INTRODUCTION}

In recent years, environmental pollution based on the form of an element has become a question of considerable public and scientific concern owing to its beneficial or toxic effect to human health and biological systems $(1,2)$. Arsenic is a toxic element for humans even at low concentration levels and exposure to arsenic can cause a variety of adverse health effects, including dermal changes, respiratory, cardiovascular, gastrointestinal, genotoxic, mutagenic, and carcinogenic effects (3). In particular, the toxicity of arsenic is highly dependent on its chemical forms $(4,5)$. In natural water, arsenic exists predominantly in inorganic arsenic species such as As(III) and As(V). In addition, a minor amount of organic arsenic compound was also detected (6). It was reported that inorganic arsenic species are more toxic than the organic ones, and the inorganic trivalent forms are more toxic than the pentavalent ones (7). Therefore, knowledge of the speciation of arsenic in water samples is of great importance to obtaining helpful information on the toxicity and biotransformation of arsenic in fauna, flora, and humans.

In general, elemental speciation can be carried out by combining an effective separation method with a sensitive detection technique. Of the many detection techniques available, inductively coupled plasma mass spectrometry (ICP-MS)

*Corresponding autbor.

E-mail: chensbizbong62@163.com

\section{ABSTRACT}

In this paper, titanium dioxide nanotubes (TDNTs) were used as a new solid phase extraction adsorbent for on-line separation and preconcentration of inorganic arsenic species [As(III) and $A s(V)]$ prior to the determination by inductively coupled plasma mass spectrometry (ICPMS). The experimental results showed that in the $\mathrm{pH}$ range of 3.0-6.0, As(III) and As(V) were quantitatively retained on TDNTs. As(III) was only quantitatively adsorbed by TDNTs within the $\mathrm{pH}$ range of 6.0-10, while As(V) passed directly through the microcolumn without retention.

Based on the facts mentioned above, a novel method was developed for the speciation of inorganic arsenic by determining total As and $\mathrm{As}(\mathrm{III})$ at the $\mathrm{pH}$ of 5.0 and 9.0, respectively; As(V) was obtained from the difference between them. The main factors affecting the separation and determination of the analytes were also examined in detail. Under the optimized conditions, the detection limit of this method was $0.0019 \mathrm{ng} \mathrm{mL}^{-1}$ for As(III) with an enrichment factor of 75 , and the relative standard deviation was $2.5 \%$ for As(III) ( $\mathrm{n}=9$, $\mathrm{c}=1.0 \mathrm{ng} \mathrm{mL}^{-1}$ ). This method was applied for the determination of inorganic arsenic species in environmental water samples in the recovery range of $95.5-102 \%$. In order to verify the accuracy of the method, a certified reference water sample was analyzed with satisfactory results. has received increasing attention due to its ability to perform rapid multi-element detection with high sensitivity. Many effective separation procedures such as hydride generation, solid phase extraction (SPE), cloud point extraction, coprecipitation, ion exchange, chromatography, and capillary electrophoresis have been employed for the speciation of inorganic arsenic (8-14). Solid phase extraction, as an effective preconcentration and separation technique, has attracted considerable practical interest because of its major advantages: (i) simple to perform, (ii) high preconcentration factor, (iii) rapid phase separation, and (iv) ability to use with different detection techniques $(15,16)$. It is worth noting that in solid phase extraction, adsorbent material plays a fundamentally crucial role in the selective preconcentration and separation of different species of substances. Thus, the development of a new adsorbent material with high selectivity, stability, and extraction efficiency for solid phase extraction is of interest to analysts.

In recent years, nanometer-size material has shown exceptional adsorption capabilities owing to its small size, large specific surface area, excellent mechanical strength, high chemical stability, and unique electrical properties. Some nanometer-size substances, including nanometer-sized zirconium oxide, carbon nanotubes, carbon nanofibers, FeC nanoparticles, nanometer-size titanium dioxide and nanometer $\mathrm{Al}_{2} \mathrm{O}_{3}$, have been successfully used as adsorbents for the preconcentration and separation of metal, nonmetal ions and 
their speciation, as well as adsorption of organic compounds from water samples (17-24).

Titanium dioxide nanotubes (TDNTs), as a new and excellent material, have attracted great attention in the fields of photocatalysis and dye-sensitized solar cells (25, 26). It has been proved and reported in the literature (27) that TDNTs have a larger surface area (up to $400 \mathrm{~m}^{2} / \mathrm{g}$ ) than titanium dioxide nanoparticles and carbon nanotubes. In addition, TDNTs provide very attractive features such as high chemical stability, durability, corrosion-resistance, as well as being non-toxic and of low cost. All of the facts mentioned above reveal that TDNTs may be a promising candidate as adsorbers for the preconcentration and separation of different substances. Until now, however, to the best of our knowledge, studies on the application of TDNTs to the analysis of elemental speciation have received little attention. The main aim of this work was to develop TDNTs as a new adsorbent for speciation of inorganic As(III) and As(V) by ICP-MS. The adsorption characteristics of the analytes on TDNTs were investigated in detail. The proposed method has been applied to the speciation of inorganic arsenic [As(III) and As(V)] in environmental water samples with satisfactory results.

\section{EXPERIMENTAL}

\section{Instrumentation}

A Thermo Elemental X-7 ICP-MS (Thermo Elemental Corporation, USA) was used in this work. The ICP-MS operating conditions and measurement parameters are listed in Table I. The samples and standards were spiked with $2.0 \mathrm{ng} \mathrm{mL}^{-1}$ of indium internal standard before measurement.

A Model HL-2 peristaltic pump (Shanghai Qingpu Huxi Instrument Factory, P.R. China), coupled to a self-made polytetrafluoroethylene (PTFE) microcolumn (20 $\mathrm{mm} \times$ $3.0 \mathrm{~mm}$ i.d.), packed with TDNTs, was used for the preconcentration/ separation process. A minimum length of PTFE tubing with an i.d. of $0.5 \mathrm{~mm}$ was used for all connections. The $\mathrm{pH}$ values of the solutions were measured with a $\mathrm{pH}$ meter (Thermo Orion Corporation, USA), supplied with a combined electrode.

\section{Standard Solutions and Reagents}

The stock standard solutions (1.0 $\mathrm{mg} \mathrm{mL}^{-1}$ ) of As(III) and As(V) were obtained by dissolving appropriate amounts of $\mathrm{Na}_{3} \mathrm{AsO}_{3}$ and $\mathrm{Na}_{3} \mathrm{AsO}_{4} \cdot 12 \mathrm{H}_{2} \mathrm{O}$ (Tianjin Reagent Factory, Tianjin, P.R. China) in high purity deionized water. Working solutions were prepared daily by appropriate dilution of the stock solutions. All reagents used were ultrapure or at least of analytical grade. The TDNTs were synthesized in our laboratory. The specific surface area and medial aperture of TDNTs were $348 \mathrm{~m}^{2} / \mathrm{g}$ and $4.53 \mathrm{~nm}$, respectively, characterized by the linear portion of the BET plots and scanning electron microscope (Japan). High purity deionized water (18.2 M $\Omega)$, obtained with a Milli-Q ${ }^{\mathrm{TM}}$ A10 system (Millipore Corporation, USA), was used throughout this work.

\section{Column Preparation}

A PTFE microcolumn $(20 \mathrm{~mm} \times$ $3.0 \mathrm{~mm}$ i.d.), plugged with a small portion of glass wool at both ends, was filled with $100 \mathrm{mg}$ of TDNTs. Before use, $5.0 \mathrm{~mL}$ of $1.0 \mathrm{~mol} \mathrm{~L}^{-1}$ $\mathrm{HNO}_{3}$ solution and $20 \mathrm{~mL}$ of high purity deionized water were passed through the column in order to clean and condition it. Then, the column was conditioned to the desired $\mathrm{pH}$ value with $\mathrm{HNO}_{3}$ and $\mathrm{NaOH}$ solutions.

\section{General Procedure}

A portion of the aqueous sample solution containing different arsenic species was prepared, and the $\mathrm{pH}$ was adjusted to the desired value with $0.1 \mathrm{~mol} \mathrm{~L}^{-1} \mathrm{HNO}_{3}$ and $0.1 \mathrm{~mol} \mathrm{~L}^{-1} \mathrm{NaOH}$. The solution was passed through the column by using a peristaltic pump adjusted to the desired flow rate. Afterwards, the retained analytes were eluted with $2.0 \mathrm{~mL}$ of $0.30 \mathrm{~mol} \mathrm{~L}^{-1} \mathrm{NaOH}$ solution. The analytes in the resultant effluents were directly determined by ICP-MS. A blank was always taken through the whole procedure. The column could be used repeatedly after regeneration with $0.30 \mathrm{~mol} \mathrm{~L}^{-1} \mathrm{NaOH}$ solution and doubly distilled water, respectively.

TABLE I

ICP-MS Operating Parameters

$\begin{array}{ll}\text { Plasma Power } & 1.3 \mathrm{~kW} \\ \text { Plasma Argon Flow Rate } & 14 \mathrm{~L} \mathrm{~min}^{-1} \\ \text { Auxiliary Argon Flow Rate } & 0.80 \mathrm{~L} \mathrm{~min}^{-1} \\ \text { Nebulizer Argon Flow Rate } & 0.94 \mathrm{~L} \mathrm{~min}^{-1} \\ \text { Sampler Orifice (nickel) } & 1.1 \mathrm{~mm} \\ \text { Skimmer Orifice (nickel) } & 0.7 \mathrm{~mm} \\ \text { Acquisition Mode } & \text { Peak jumping } \\ \text { Number of Sweep } & 100 \\ \text { Dwell Time } & 10 \mathrm{~ms} \\ \text { Acquisition Time } & 40 \mathrm{~s} \\ \text { Number of Measurements per Peak } & 3 \\ \text { Isotope } & { }^{75} \mathrm{As} \text { and }{ }^{115} \mathrm{In}\end{array}$




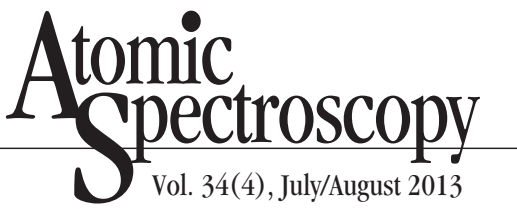

\section{RESULTS AND DISCUSSION}

\section{Effect of pH}

Owing to the great effect on the surface of the adsorbent, the $\mathrm{pH}$ value plays a very important role with respect to the adsorption of different species of arsenic on the TDNTs. For this reason, the effect of $\mathrm{pH}$ on the adsorption of the studied species on the TDNTs was investigated according to the procedure mentioned above. The adsorption percentage was calculated based on the difference between the amounts of arsenic in the starting sample and the solution outflow from the column. The results are shown in Figure 1. It was obvious that in the $\mathrm{pH}$ range of 3.0-6.0, As(III) and As(V) were quantitatively retained on the TDNTs with an adsorption percentage above 95.0\%; As(III) was only quantitatively adsorbed by the TDNTs within the $\mathrm{pH}$ range of 6.0-10; while As(V) was not quantitatively retained on the adsorbent at the same $\mathrm{pH}$ range. Thus, it was possible that by selection of a proper $\mathrm{pH}$, As(III) could be effectively separated from As(V) on the TDNTs. In this work, a pH of 5.0 was selected for the preconcentration and determination of total As, and a $\mathrm{pH}$ of
9.0 was used for the separation of As(III) from As(V) .

\section{Elution of Analytes}

It can be seen from Figure 1 that the adsorption percentages of the analytes on the TDNTs decreased significantly at a high $\mathrm{pH}$ value $(\mathrm{pH}$ >9.5). Therefore, a NaOH solution at a different concentration was used as the stripping agent to elute the retained analytes from the microcolumn packed with TDNTs. It was found in the experiment that the retained species could be eluted quantitatively with the solution of $0.30 \mathrm{~mol} \mathrm{~L}^{-1} \mathrm{NaOH}$.

Furthermore, the effect of eluent volume on the recoveries of the analytes was also studied by keeping the concentration of $0.30 \mathrm{~mol} \mathrm{~L}^{-1}$ $\mathrm{NaOH}$ solution. The experimental results showed that quantitative recoveries (>94.0\%) could be obtained with $2.0 \mathrm{~mL}$ of $0.30 \mathrm{~mol} \mathrm{~L}^{-1}$ $\mathrm{NaOH}$ solution. Therefore, $2.0 \mathrm{~mL}$ of $0.30 \mathrm{~mol} \mathrm{~L}^{-1} \mathrm{NaOH}$ solution was used for the quantitative elution of the analytes in this work.

\section{Influence of Sample Solution Flow Rate}

The flow rate of the sample solution is also a very important para- meter for the quantitative retention of As(III) on the adsorbent and for the length of a complete analysis. Its effect on the adsorption of the analytes was investigated by passing $20 \mathrm{~mL}$ of sample solution through the microcolumn with the peristaltic pump at the flow rate

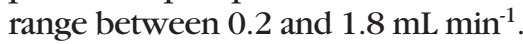
It can be seen from Figure 2 that the retention of the analytes was practically unchanged up to a flow rate of $1.0 \mathrm{~mL} \mathrm{~min}^{-1}$, but the retention decreased at a higher flow rate due to a decrease in the adsorption kinetics. Accordingly, all subsequent experiments were performed

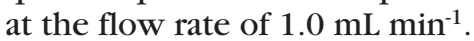

\section{Effect of Sample Solution Volume}

In order to explore the possibility of enriching low concentrations of the analytes from the large sample volume, the effect of sample volume on the adsorption of the analytes was studied at selective $\mathrm{pH}$ values. For this purpose, 20, 50, $100,150,200$, and $250 \mathrm{~mL}$ of the sample solutions containing $10 \mathrm{ng}$ As(III) were passed through the microcolumn at the flow rate of $1.0 \mathrm{~mL} \mathrm{~min}{ }^{-1}$. The results in Figure 3 indicated that quantitative recoveries (>90\%) were obtained for a sam-

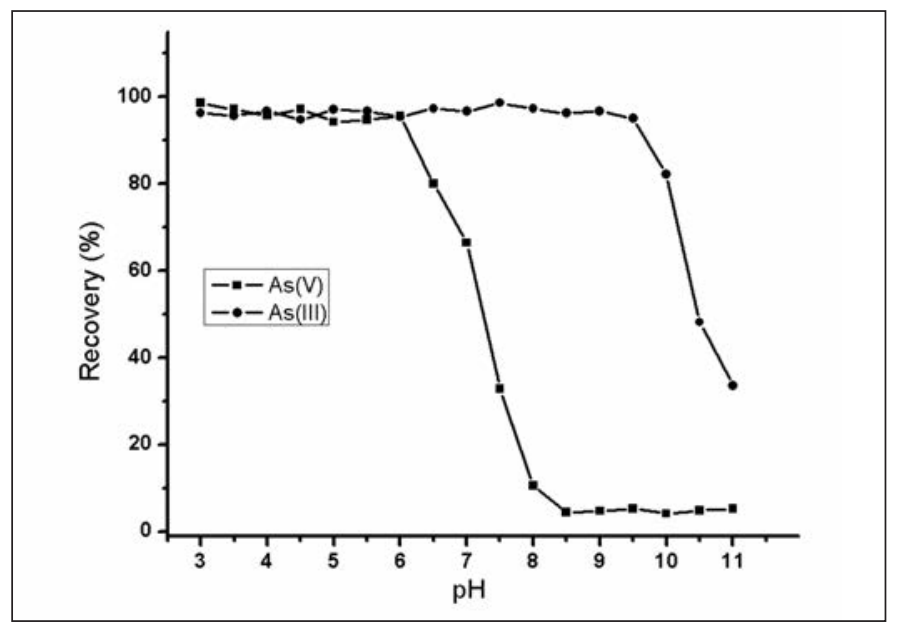

Fig. 1. Effect of $p H$ on the adsorption of the analytes on TDNTs. As(III) and As(V): $3.0 \mathrm{ng} \mathrm{mL}^{-1}$; sample volume: $20 \mathrm{~mL}$.

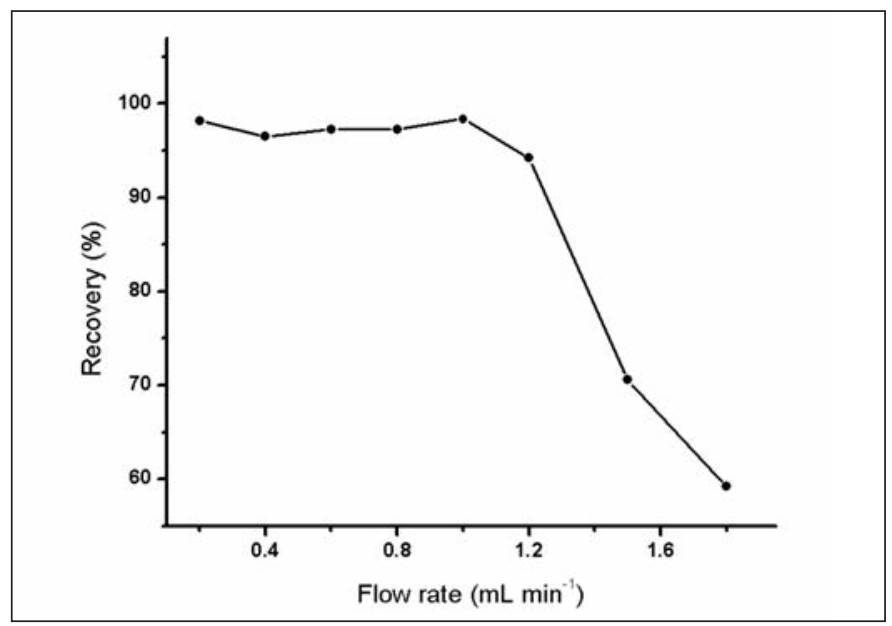

Fig. 2. Effect of sample flow rate on the recovery of the analytes on TDNTs. pH: 5.0; sample volume: $20 \mathrm{~mL}$; As(III): $3.0 \mathrm{ng} \mathrm{mL}^{-1}$. 
ple volume up to $150 \mathrm{~mL}$. In the present work, $20 \mathrm{~mL}$ of sample solution was used for the preconcentration of the analyte from the sample, and the adsorbed ions can be eluted with $2.0 \mathrm{~mL}$ of $0.30 \mathrm{~mol} \mathrm{~L}^{-1}$ $\mathrm{NaOH}$ solution. Thus, an enrichment factor of 75-fold was achievable in this work.

\section{Effect of Interfering Ions}

The effect of potential interference ions in the samples on the preconcentration/separation and determination of the analytes was investigated. In the experiments, solutions of $3.0 \mathrm{ng} \mathrm{mL}^{-1}$ As(III) containing the added interfering ions were treated according to the recommended procedure under the optimum conditions. The tolerance limit of coexisting ions is defined as the largest amount making the recovery of the analytes less than $90 \%$. The results obtained are summarized in Table II. It can be seen that the presence of the studied cations and anions has no obvious effects on the determination of the analytes in the range of their amounts tested.

\section{Adsorption Capacity}

The adsorption capacity, as an important parameter for the evaluation of adsorbent, was investigated by a method provided in the literature (28). Aliquots of $20 \mathrm{~mL}$ of a series of concentrations (5.0-30 $\mu \mathrm{g} \mathrm{mL}^{-1}$ ) were adjusted to the $\mathrm{pH}$ of 5.0 , then preconcentrated and eluted. The amount of As(III) adsorbed at each concentration level was determined by this method. Breakthrough curves were obtained by plotting the analyte concentrations ( $\left.\mu \mathrm{g} \mathrm{mL} \mathrm{m}^{-1}\right)$ versus the milligrams of the analytes adsorbed per gram of adsorbent. The adsorption capacity calculated from the breakthrough curve was $7.85 \mathrm{mg} \mathrm{g}^{-1}$ for As(III).

\section{Effect of As(V)/As(III) Ratio}

The effect of As(V)/As(III) ratio on the analytical results during the separation and preconcentration process was evaluated. Various synthetic samples with different As(V) and As(III) concentration ratios were used. The experimental results indicated that the species of arsenic completely separated and recovered quantitatively with a As(V) and As(III) ratio varying from 1.0 to 25 .

\section{Column Reuse}

The stability and the potential regeneration of the column packed with TDNTs were assessed by monitoring the changes in the recovery of the analytes. The column can be reused after regeneration with $20 \mathrm{~mL}$ of $0.30 \mathrm{~mol} \mathrm{~L}^{-1} \mathrm{NaOH}$ solution and $20 \mathrm{~mL}$ deionized water, respectively, and is stable up to 50 adsorptionelution cycles without obvious decrease in the recoveries of the analytes.

\section{Analytical Performances}

The important analytical parameters of the proposed method, including precision, linear range of calibration curve, and detection limits, were carried out under the optimum experimental conditions. According to the IUPAC definition, the limits of detection were calculated as the concentration of an analyte yielding a signal equivalent to three times the standard deviation of the blank value. The detection limit $(3 \sigma)$ for the method was $0.0019 \mathrm{ng} \mathrm{mL}^{-1}$ for As(III), with an enrichment factor of 75 . The relative standard deviation for As(III)

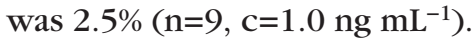
The linear range of this method was from 1.0 to $100 \mathrm{ng} \mathrm{mL}^{-1}$, with the correlation coefficient better than 0.9995 .

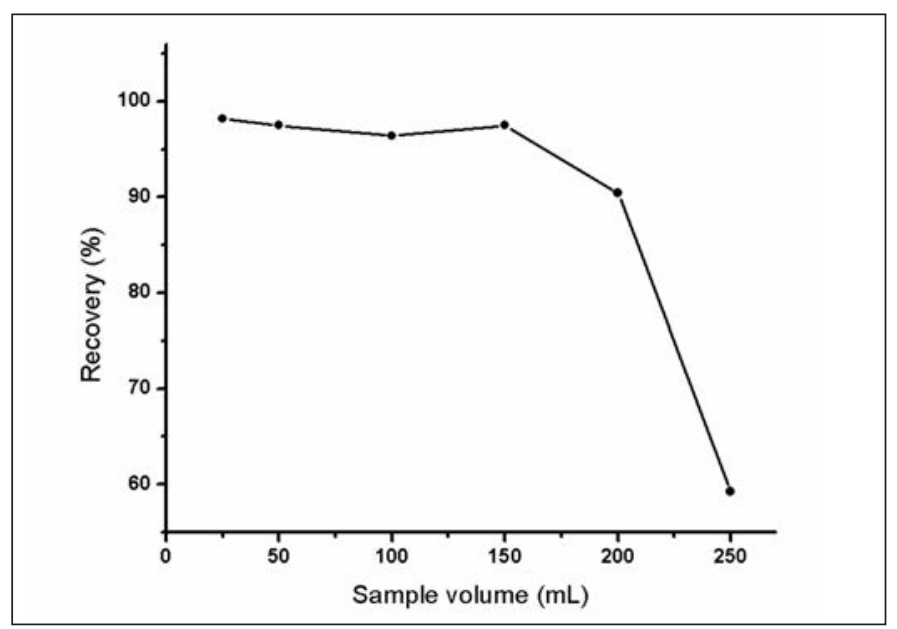

Fig. 3. Effect of sample solution volume on the recovery of the analytes on TDNTs. pH: 5.O; As(III): $10 \mathrm{ng}$.
TABLE II Effect of Coexisting Ions

\begin{tabular}{lc}
\hline Coexisting Ion & Concentration Ratio \\
\hline $\mathrm{Na}^{+}, \mathrm{K}^{+}$ & 10000 \\
$\mathrm{Ca}^{2+}, \mathrm{Mg}^{2+}$ & 5000 \\
$\mathrm{Fe}^{3+}, \mathrm{Al}^{3+}$ & 500 \\
$\mathrm{PO}_{4}{ }^{3-}, \mathrm{SiO}_{3}{ }^{2-}, \mathrm{SO}_{4}{ }^{2-}$ & 2000 \\
$\mathrm{Cl}^{-}$ & 5000
\end{tabular}

${ }^{a}$ Foreign ion to analyte. 


\section{Atomic Spectroscopy \\ 1 Vol. 34(4), July/August 2013}

TABLE III

Analytical Results and Recoveries of As(III) and As(V) in Water Samples

\begin{tabular}{|c|c|c|c|c|c|c|c|}
\hline & \multicolumn{2}{|c|}{ Added (ng mL $\left.\mathrm{m}^{-1}\right)$} & \multicolumn{3}{|c|}{ Found (ng $\mathrm{mL}^{-1}$ ) } & \multicolumn{2}{|c|}{ Recovery (\%) } \\
\hline As(III) As(V) & As(III) & As $(V)^{a}$ & Total As & As(III) & $\operatorname{As}(V)$ & As(III) & As $(V)$ \\
\hline \multirow[t]{2}{*}{ Han River Water } & 0 & 0 & $1.31 \pm 0.06$ & $1.75 \pm 0.08$ & $3.06 \pm 0.15$ & - & - \\
\hline & 2.0 & 2.0 & $3.22 \pm 0.19$ & $3.79 \pm 0.21$ & $7.01 \pm 0.35$ & 95.5 & 102 \\
\hline \multirow[t]{2}{*}{ Dongxi Lake Water } & 0 & 0 & $1.95 \pm 0.13$ & $1.47 \pm 0.07$ & $3.42 \pm 0.17$ & - & - \\
\hline & 2.0 & 2.0 & $3.92 \pm 0.20$ & $3.40 \pm 0.15$ & $7.32 \pm 0.31$ & 98.4 & 96.3 \\
\hline \multirow[t]{2}{*}{ Wastewater } & 0 & 0 & $8.21 \pm 0.25$ & $6.35 \pm 0.27$ & $14.56 \pm 0.48$ & - & - \\
\hline & 5.0 & 5.0 & $13.08 \pm 0.54$ & $11.26 \pm 0.39$ & $24.34 \pm 1.09$ & 97.4 & 98.2 \\
\hline
\end{tabular}

${ }^{\text {a }}$ Calculated value.

\section{Sample Analysis}

Under the optimized conditions, this method was applied to the determination of trace As(III), $\mathrm{As}(\mathrm{V})$, and total As in water samples such as Han River water, Dongxi lake water, and wastewater. The water samples were filtered through a $0.25-\mu \mathrm{m}$ membrane filter, and then analyzed as soon as possible. The blank was prepared exactly as the samples, except no analytes were added. The analytical results along with the recoveries for the spiked samples are listed in Table III. As can be seen, the recoveries for different inorganic species of arsenic were from $95.5-102 \%$.

In order to validate the accuracy of the proposed method, a certified reference material of GSB Z5000488 water sample (Beijing, P.R. China) was analyzed for As(III), As(V), and total As. The results in Table IV show that the analytical results of this method are in agreement with the certified values.

\section{CONCLUSION}

In conclusion, the adsorption behaviors of As(III) and As(V) on titanium dioxide nanotubes (TDNTs) were investigated systematically by inductively coupled plasma mass spectrometry (ICPMS). Based on the adsorption selectivity of As(III) and As(V) on the TDNTs, a novel method was presented for on-line separation and preconcentration of the inorganic

TABLE IV

Analytical Results of Analytes in Standard Reference Material

\begin{tabular}{lccc}
\hline Sample & Species & $\begin{array}{c}\text { Found } \\
\left(\mathrm{ng} \mathrm{mL}^{-1}\right)\end{array}$ & $\begin{array}{c}\text { Certified } \\
\left(\mathrm{ng} \mathrm{mL}^{-1}\right)\end{array}$ \\
\hline Water (GSB Z50004-88) & Total As & $49.1 \pm 3.2$ & $47.9 \pm 2.5$ \\
& As(III) & $5.9 \pm 0.0 .29$ & - \\
& As(V) & $44.5 \pm 2.7$ & - \\
\hline
\end{tabular}

arsenic species of As(III) and As(V), using a microcolumn packed with TDNTs coupled with the determination by ICP-MS. The experimental results indicate that at the desired $\mathrm{pH}$ value, total As can be quantitatively determined, and As(III) was also quantitatively separated from total As. The As(III) retained on the TDNTs can be easily desorbed with $2 \mathrm{~mL}$ of $0.30 \mathrm{~mol} \mathrm{~L}^{-1} \mathrm{NaOH}$, and no carryover is observed in the next analysis. The proposed method was applied to the separation/preconcentration and determination of the speciation of inorganic arsenic in environmental water samples with satisfactory results.

\section{ACKNOWLEDGMENT}

Financial support from the Nature Science Foundation and the Education Department Foundation of Hubei Province in China is gratefully acknowledged.

Received May 8, 2013.

\section{REFERENCES}

1. I.N. Pasias, N.S. Thomaidis, and E.A. Piperaki, Microchem. J. 108, 1 (2013).

2. B. Patrick and D. Pierre, At. Spectrosc. 31(6), 175 (2010).

3. N. Zhang, C. Wei, and L. Yang, Microchem. J. 110, 169(2013).

4. X. Yan, X. Yin, X. He, Y. Jiang, Anal. Chem. 74(9), 2162 (2002).

5. D. Sanchez-Rivera, O Perales-Perez, and F.R. Roman, Anal. Meth. 5(6), 1583 (2013).

6. J. Michon, V. Deluchat, R.A. Shukry, C. Dagot, and J. Bollinger, Talanta 71(1), 479 (2007).

7. L.O. Leal, R. Forteza, and V. Cerdá, Talanta 69, 500 (2006).

8. G. Cristina, C.A. Ma, H. Paloma, and B. Pilar, At. Spectrosc.31(1), 27 (2010).

9. R.E. Rivas, I. López-García, and M. Hernández-Córdoba, Spectrochim. Acta Part B 64(4), 329 (2009).

10. P. Smichowski, L. Valiente, and A. Ledesma, At. Spectrosc. 23(3), 92 (2002). 
11. J.T. Elteren, V. Stibilj, and Z. Šlejkovec, Water Res. 36(12), 2967 (2002).

12. H. Wu, X. Wang, B. Liu, Y. Liu, S. Li, J. Lu, J. Tian, W. Zhao, and Z. Yang, Spectrochim. Acta Part B 66(1), 74 (2011).

13. S. Karthikeyan, K. Honda, O. Shikino, and S. Hirata, At. Spectrosc. 24(3), 79 (2003).

14. X. Liu, W. Zhang, Y. Hu, and $\mathrm{H}$. Cheng, Microchem. J. 108, 38 (2013).

15. V.A. Lemos, L.S.G. Teixeira, M.A. Bezerra, A.C.S. Costa, J.T. Castro, L.A.M. Cardoso, D.S. de Jesus, E.S. Santos, P.X. Baliza, and L.N. Santos, Appl. Spectrosc. Rev. 43, 303 (2008).

16. V. Camel, Spectrochim. Acta Part B 58, 1177 (2003).

17. R. Yinzhe, F. Zhefeng, and W. Jianying, Microchim. Acta 158(3-4), 227 (2007).

18. Y. Liu, Y. Li, and L. Yang, Microchem. J. 104, 56 (2012).

19. S. Chen, M. Xiao, D. Lu, Z. Hu, and X. Zhan, At. Spectrosc. 28(3), 90 (2007).

20. W. Yiwei, J. Yinyan, H. Deyan, W. Fang, and Z. Junxia, Microchim. Acta 159 (3-4), 333 (2007).

21. S. Xu, M. Zheng, X. Zhang, J. Zhang, and Y. Lee, Microchem. J. 101, 70 (2012).

22. D. Chen, J. Deng, J. Liang, J. Xie, K.Huang, and C. Hu, Anal. Meth. 5(3), 722 (2013).

23. Y. Cui, X. Chang, Y. Zhai, X. Zhu, H. Zheng, and N. Lian, Microchem. J. 83, 35 (2006).

24. S. Chen, L. Zhu, D. Lu, X. Chen, and X. Zhou, Microchim. Acta 169(12), 123 (2010).

25. V. Idakiev, Z.Y. Yuan, T. Tabakova, and B.L. Su, Appl. Catal. A 281, 149 (2005).

26. J.C. Xu, M. Lu, X.Y.Guo, and I. Li, J. Mol. Catal. A 226, 123 (2005).

27. C.C. Tsai and H.S. Teng, Chem. Mater. 16, 4352 (2004).

28. A. Maqieira, H.AM. Elmahadi, and R. Puchades, Anal. Chem. 66, 3632 (1994). 